\title{
Generalist host species drive Trypanosoma cruzi vector infection in oil palm plantations in the Orinoco region, Colombia
}

Diana Erazo ${ }^{*}$, Nicole L. Gottdenker², Camila González ${ }^{3}$, Felipe Guhl ${ }^{3}$, Monica Cuellar ${ }^{4}$, Troy J. Kieran ${ }^{5}$, Travis C. Glenn ${ }^{5}$, Juan D. Umaña and Juan Cordovez ${ }^{1}$

\begin{abstract}
Background: Oil palm plantation establishment in Colombia has the potential to impact Chagas disease transmission by increasing the distribution range of Rhodnius prolixus. In fact, previous studies have reported Trypanosoma cruzi natural infection in R. prolixus captured in oil palms (Elaeis guineensis) in the Orinoco region, Colombia. The aim of this study is to understand T. cruzi infection in vectors in oil palm plantations relative to community composition and host dietary specialization by analyzing vector blood meals and comparing these results to vectors captured in a native palm tree species, Attalea butyracea.

Methods: Rhodnius prolixus nymphs $(n=316)$ were collected from A. butyracea and E. guineensis palms in Tauramena, Casanare, Colombia. Vector blood meals from these nymphs were determined by amplifying and sequencing a vertebrate-specific 125 rRNA gene fragment.

Results: Eighteen vertebrate species were identified and pigs (Sus scrofa) made up the highest proportion of blood meals in both habitats, followed by house mouse (Mus musculus) and opossum (Didelphis marsupialis). Individual bugs feeding only from generalist mammal species had the highest predicted vector infection rate, suggesting that generalist mammalian species are more competent hosts for T. cruzi infection .

Conclusions: Oil palm plantations and A. butyracea palms found in altered areas provide a similar quality habitat for R. prolixus populations in terms of blood meal availability. Both habitats showed similarities in vector infection rate and potential host species, representing a single T. cruzi transmission scenario at the introduced oil palm plantation and native Attalea palm interface.
\end{abstract}

Keywords: Trypanosoma cruzi, Rhodnius prolixus, Elaeis guineensis, Blood meal analysis, Host community composition, Generalist host

\section{Background}

Land-use change (LUC), caused by urbanization, agricultural expansion and intensification, leads to habitat fragmentation and loss of animal and plant biodiversity. Species responses to LUC are complex, potentially depending on their functional traits [1]. Typically in a community, large, slower breeding, less-mobile species

\footnotetext{
${ }^{*}$ Correspondence: erazodiana1@gmail.com

${ }^{1}$ Grupo de Investigación en Biología Matemática y Computacional (BIOMAC), Universidad de los Andes, Bogota, Colombia

Full list of author information is available at the end of the article
}

as well as dietary and habitat specialists are the most vulnerable to LUC [2-8]. The specialist-generalist concept is based on how natural selection promotes specialized strategies among species by showing an evolutionary trade-off between specializing to perform few activities well, and generalizing to perform many activities fairly [9]. Specialists usually benefit from undisturbed landscapes, where there are many environmental niches in which to specialize, whereas generalists can often thrive in anthropogenically disturbed landscapes [10-13]. In fact, niche evolution theory predicts that habitat 
fragmentation should negatively affect specialist species in a community [14].

Recent studies in the tropics observe vertebrate specialist species declines as a consequence of LUC. Birds have been suggested as the most sensitive class negatively affected by forest conversion into agriculture around the world [15]. For instance, forest cover loss was the principle threat to specialist birds in the tropical rainforest of Lacandona in Mexico [16]. In general, mammals are less sensitive to habitat disturbance compared to birds, perhaps due to a higher abundance of generalist species, such as small mammals [15]. Nonetheless, anthropogenic intervention in tropical forests has caused a decrease in small mammal species that are forest specialists, favoring those that tolerate human activities in Costa Rica [17], Paraguay [18] and Venezuela [19]. Additionally, mediumsized opportunistic carnivores-omnivores, such as opossums and raccoons, tend to increase in abundance in disturbed landscapes $[20,21]$. As a result, land use alteration is expected to decrease specialist vertebrate species, whereas generalist mammal species such as common opossum increases.

Generalist rodents, opossums, raccoons, and other opportunistic mammals are often considered to be important reservoirs for vector-borne diseases [22-25]. In many cases, these species are associated with rapid reproduction [26, 27], introducing high numbers of susceptible individuals into a population at a relatively high rate. In addition, based on the 'pace of life' hypothesis, fast-lived species are expected to invest less in acquired immunity compared to long-lived species [28-30]. Therefore, LUC favoring 'fast-living' generalist/opportunistic species could promote vector-borne disease transmission. Few studies have assessed the role of generalist species on vector-borne transmission. For instance, generalist rodents often harbor more diverse flea communities and higher flea loads (number of fleas per host) [31]. Another example from a modeling approach showed that dietary generalist species could amplify West Nile virus transmission compared to specialist species [32]. Clearly, the degree of habitat specialization of different host species should be considered when evaluating mechanisms of changes in vector-borne pathogen transmission in association with LUC.

Chagas disease is caused by a multi-host vector-borne pathogen and its transmission may be strongly affected by changes in host community as a consequence of LUC [33]. The disease is caused by the parasite Trypanosoma cruzi and transmitted by insects within the subfamily Triatominae. Chagas disease is endemic in Latin America affecting 7 million people, with a burden of 12,000 deaths per year [34]. The parasite transmission involves nearly a hundred mammal species, yielding domestic and sylvatic cycles of transmission [35]. Therefore, LUC, which alters mammal community composition, could potentially alter the disease transmission dynamics, requiring a particular understanding of the ecological transmission context for each LUC scenario [36].

A recent study in the Orinoco basin in Colombia showed that the mammal community in savannas and oil palm plantations (Elaeis guineensis) was similar, dominated by generalist species, and less rich compared to gallery forests [37]. In addition, Rhodnius prolixus, the main vector in the region, and a true palm specialist [38, 39 ], is capable of invading oil palm crowns, potentially introducing T. cruzi [40]. Thus, T. cruzi transmission is an interesting system for studying the role of dietary generalist versus specialist mammal host species in vectorborne disease transmission in agricultural landscapes, such as oil palm plantations, which are leading producers of biodiesel worldwide [41]. The rapid expansion of the oil palm industry in Colombia [42] could therefore have a significant impact on vector-host-T.cruzi transmission relationships.

The aim of this study was to understand the role of host community composition and the relative contribution of domestic and sylvatic mammal species on T. cruzi maintenance and transmission in oil palm plantations and adjacent native palm vegetation. This study has three specific objectives: (i) to analyze $R$. prolixus blood meals in oil palm plantations (African oil palms) in the Orinoco basin and investigate the importance of generalist host species in T. cruzi transmission in this agricultural landscape; (ii) to compare vector blood meals in oil palms with adjacent native $A$. butyracea palms, the natural habitat of $R$. prolixus in the region; and (iii) to determine if vector infection in both palm species is responding to similar drivers in terms of host dietary specialization.

\section{Methods}

\section{Study area and triatomine sampling}

Fieldwork was conducted in Los Potrillos, Tauramena municipality $\left(4^{\circ} 59^{\prime} 1^{\prime \prime} \mathrm{N}, 72^{\circ} 36^{\prime} 36^{\prime \prime} \mathrm{W}\right)$ located in the department of Casanare, from August 2016 to July 2017. The region has bimodal seasonality [43] and we visited the study site twice per season, in August 2016 and July 2017 for the rainy season, and in December 2016 and March 2017 for the dry season. Each visit lasted 10 nights. We sampled a 2 ha Attalea butyracea forest and an adjacent Elaeis guineensis plantation (11 ha), for 5 consecutive nights per habitat.

Traps live baited with chickens were used for Triatomine collection [44]. Traps were set at 17:00 $\mathrm{h}$ within or next to the palm tree crowns, and revised the next day at 7:00 $\mathrm{h}$. All available $A$. butyracea were sampled $(n=79)$ while for E. guineensis a subsample was selected based on 
the height of the crown suitable for sampling $(n=103)$ (see Additional file 1: Figure S1 for traps arrangement in the study site). Collected triatomines were placed in ethanol $70 \%$. Palm trees were geo-referenced and marked for identification.

\section{Triatomine infection and blood meal analysis}

We captured $316 R$. prolixus nymphs (N1 to N5 nymphal stages) from the E. guineensis plantation $(n=148)$ and the $A$. butyracea forest $(n=168)$, to analyze for $T$. cruzi infection and blood meals. DNA was extracted using phenol:clorophorm:isoamyl alcohol protocol as described elsewhere [45].

Trypanosoma cruzi infection for selected insects was determined by the amplification of mini-circle specific primers 121 (5'-AAA TAA TGT ACG G(T/G)G AGA TGC ATG A-3') and 122 (5'-GGG TTC GAT TGG GGT TGG TGT-3') to obtain an amplicon of $330 \mathrm{bp}$ [46]. DTU characterization was conducted by amplifying the intergenic region of the non-transcribed mini-exon gene from the parasite using primers TCC $\left(5^{\prime}-C C C\right.$ CCC TCC CAG GCC ACA CTG-3'), TCI (5'-GTG TCC GCC ACC TCC TTC GGG CC-3'), and TC2 (5'-CCT GCA GGC ACA CGT GTG TGT G-3') [47].

For blood meal analysis, we amplified DNA performing two PCR rounds following Kieran et al. [45]. The firstround PCR amplified a $12 S$ rRNA region (145 bp) typically used for vertebrate detection (F: 5'-CAA ACT GGG ATT AGA TAC C-3'; R: 5'-AGA ACA GGC TCC TCT AG-3') [48] with TruSeq compatiable adaptor fusions [43]. PCR cycling conditions considered an initial denaturation at $98^{\circ} \mathrm{C}$ for $3 \mathrm{~min}$, followed by 40 cycles at $95^{\circ} \mathrm{C}$ for $30 \mathrm{~s}, 63{ }^{\circ} \mathrm{C}$ for $1 \mathrm{~min}, 72{ }^{\circ} \mathrm{C}$ for $1 \mathrm{~min}$, and a final extension at $72{ }^{\circ} \mathrm{C}$ for $5 \mathrm{~min}$. Positive amplicons were pooled in equal concentration and cleaned with SPRIbeads (1:1 ratio).

For the second-round PCR we used Ilumina TruSeqHT compatible $8 \mathrm{nt}$ indexed primers [49]. Reactions and thermocycler conditions were described by Kieran et al. [45]. We cleaned the library product and removed the primers using 1:1 ratio of SPRI-beads. Finally, the libraries were sent for sequencing on an Illumina MiSeq with Paired-End 300 reads (University of Georgia Genomics Facility).

Bioinformatics analyses were conducted using $\mathrm{Mr}$ Demuxy v1.2.0 (https://pypi.python.org/pypi/ Mr_Demuxy/1.2.0), Geneious v10 (Biomatters Limited, NJ), and the software package QIIME v1.9.1 [50]. First, we demultiplexed the $12 \mathrm{~S}$ amplicon pool using Mr Demuxy v1.2.0 to remove internal barcodes and primers. Then demultiplexed files were transferred to Geneious v10 to set paired-reads (size $145 \mathrm{bp}$ ) and trimmed for removing low quality bases (0.001 score). Finally, we imported data into QIIME v1.9.1 for assigning data Operational Taxonomic Unit (OTU), using UCLUST (similarity: 95\%), based on a previously compiled $12 S$ reference database. For each sample, the OTU identification showed the total number of reads per species and those with less than $10 \%$ of total reads hits were removed.

The $12 \mathrm{~S}$ reference database consisted on the $12 \mathrm{~S}$ DNA sequences of vertebrate species reported in the Orinoco and its bordering regions (Amazonian and Andean) [51-54], downloaded from GenBank. When the complete $12 S$ sequence of a designated species was missing, we included an alternative sequence corresponding to a closely related species at a higher taxonomic level (genus or family). All reference sequences corresponded to the $12 S \mathrm{rRNA}$ gene, $145 \mathrm{bp}$ region. For reference database see Additional file 2 and for taxonomy see Additional file 3.

We did not include chicken (Gallus gallus) reads to account for contamination coming from the baited live traps used for triatomine capture. Additionally, we performed an additional PCR to samples reporting human reads to determine contamination by amplifying the human beta globin gene (268 bp) using primers GH20/ PC04 [55]. The human beta globin gene amplification is commonly used as a control for human clinical samples subject to molecular analysis [56]. In addition, this set of primers (GH20/PC04) has been used by other vector blood meal studies to confirm presence/absence of contamination with human DNA [57].

For data visualization, we developed an interaction network for each habitat where nodes represented $R$. prolixus and identified vertebrate species (OTUs). Links are unidirectional and move from every identified vertebrate species to vector, because they provide food for $R$. prolixus. Link weights were determined separately for each habitat, by normalizing the number of blood meals of each identified species. Therefore, the link weight between the vertebrate species presenting the highest number of blood meals in a particular habitat and $R$. prolixus is 1 .

\section{Data analysis}

A Chi-square test of independence was used to measure the dependence between taxonomic class, taxonomic order, species identified in vector blood meals, and habitat type. A generalized linear model with binomial error distribution was used to test the effects of most abundant mammal species on T. cruzi infection in R. prolixus. A Pearson correlation was used to test the relationship between host body size and infection in $R$. prolixus, for the study site and discriminated by habitat. Skin surface 
area has been suggested as a proper way to reflect host body size. However, such data are not available, thus we used the allometric scaling relationship between body mass $M$ and skin surface $A$ given by the expression $A \alpha$ $M^{2 / 3}$ [58]. Body mass and size for each host species are provided in Additional file 1: Table S1. When more than one host species was found in the a single vector blood meal, we used the average body size.

We used regression tree models to evaluate the relationship between vector infection prevalence and habitat associations of identified potential host species (domestic and sylvatic species). We divided sylvatic species into two groups, ecological specialist and generalist species based on feeding preferences [59]. Only omnivores were considered as true generalist species (see Additional file 1: Table S1). Presence/absence of identified potential host species was the explanatory variable, thus the detection of any ecological species (domestic, specialist, and generalist) in an individual would be binomial (1 for presence and 0 for absence) for a specific category. Finally, we computed Moran's $I$ index for determining spatial aggregation in the abundance of blood meal species identified in $R$. prolixus. Moran's $I$ gives values ranging from -1 to +1 . $I$ equals zero when there is no spatial autocorrelation $\left(\mathrm{H}_{0}\right)$, negative when there is negative autocorrelation and positive when data presents a clustering pattern.

We visualized $R$. prolixus and identified vertebrate species (OTUs) networks using the interactive platform Gephi [60]. One network is depicted per habitat, in which links are unidirectional from identified vertebrate species, that provide blood meal, to the vector. Link weights are specific and normalized for each habitat. We used $\mathrm{R}$ version 3.3.2 [61] and the RStudio Integrated Development Environment (IDE) for the analyses. Statistical analysis was conducted using the base package. We used the rpart package to perform the regression tree models [62]. For computing the Moran's I index we used the ape package [63].

\section{Results}

\section{Triatomine infection and blood meals}

Triatomine infection rate was similar between the two habitats: $75 \%$ in the oil palm plantation $(111 / 148)$ and $76 \%$ in the A. butyracea forest (125/165). The obtained DTU in 22 examined $R$. prolixus individuals corresponded to TcI.

We did not detect human beta globin gene in any of the processed samples, suggesting contamination in steps performed before $12 S$ amplification (insect collection and/or DNA extraction), so no human blood source was considered in the study.

We detected vertebrate DNA in $94.6 \%$ of $R$. prolixus samples $(n=299)$. Blood meal analysis detected a total of
18 vertebrate species, consisting of 14 mammals, 3 birds, and 1 reptile (Fig. 1). Mammals comprised $95.9 \%$ of vector blood meals, while birds and reptiles constituted 3.4\% and $0.7 \%$, respectively. There was no significant association between taxonomic class and habitat type $\left(\chi^{2}=1.75\right.$, $d f=2, P=0.41$ ). The pig (Sus scrofa) made up the highest proportion of blood meals with $59.2 \%$, followed by the house mouse (Mus musculus) (19.6\%), and opossum (Didelphis $s p)(8.7 \%)$. This ranking pattern was maintained in the A. butyracea forest and the oil palm plantation (Tables 1, 2).

Rhodnius prolixus from both habitats shared blood meals of four mammalian orders: Artiodactyla, Carnivora, Marsupialia and Rodentia. Three additional mammal orders were identified in the A. butyracea forest, Chiroptera (5\%), Primates (1\%) and Xenarthra (1\%) (Tables 1,2). There was a significant association between taxonomic order and habitat type $\left(\chi^{2}=22.2, d f=6\right.$, $P=0.001)$. Species composition varied between habitats. The $A$. butyracea forest had more diverse blood meal sources (16 species) compared to the E. guineensis plantation ( 9 species), and the association between species and habitat type was significant $\left(\chi^{2}=29.9, d f=13, P=0.005\right)$. However, when considering solely shared identified species (Bos taurus, Didelphis sp., M. musculus, Procyon sp. and Sus scrofa), which were the great majority in both habitats (A. butyracea: $85 \%$ and E. guineensis: 97\%), the association was not significant $\left(\chi^{2}=8.37, d f=4, P=0.08\right)$.

We found $R$. prolixus individuals with multiple blood meals (Table 3). Double species were detected in $26.6 \%$ $(n=84)$ and triple species were detected in $4.7 \%(n=15)$, although $63.3 \%$ of the samples had a single blood meal $(n=200)$.

\section{Blood meals and T. cruzi infection}

The regression tree analysis shown in Fig. 2 has T. cruzi infection in vectors as response variable and domestic, generalist, and specialist sylvatic mammal species presence as explanatory variables. In the tree non-terminal and terminal nodes are illustrated as circles and rectangles, respectively. The main node at the top of the tree shows the number of individuals evaluated for this tree and subsequent nodes are labeled with the predicted infection rate and the number of individuals that corresponded to the node. Links between nodes are labeled with an explanatory variable, showing its value ( 1 for presence and 0 for absence).

The regression tree explained $77 \%$ of the total variance in the response variable. Predicted infection rate was the lowest for individuals feeding exclusively from specialist mammal species, such as Cebus sp., bats (Artibeus sp. and Myotis sp.), specialist rodents (Proechimys sp. and Coendou sp.) and anteater (Tamandua 


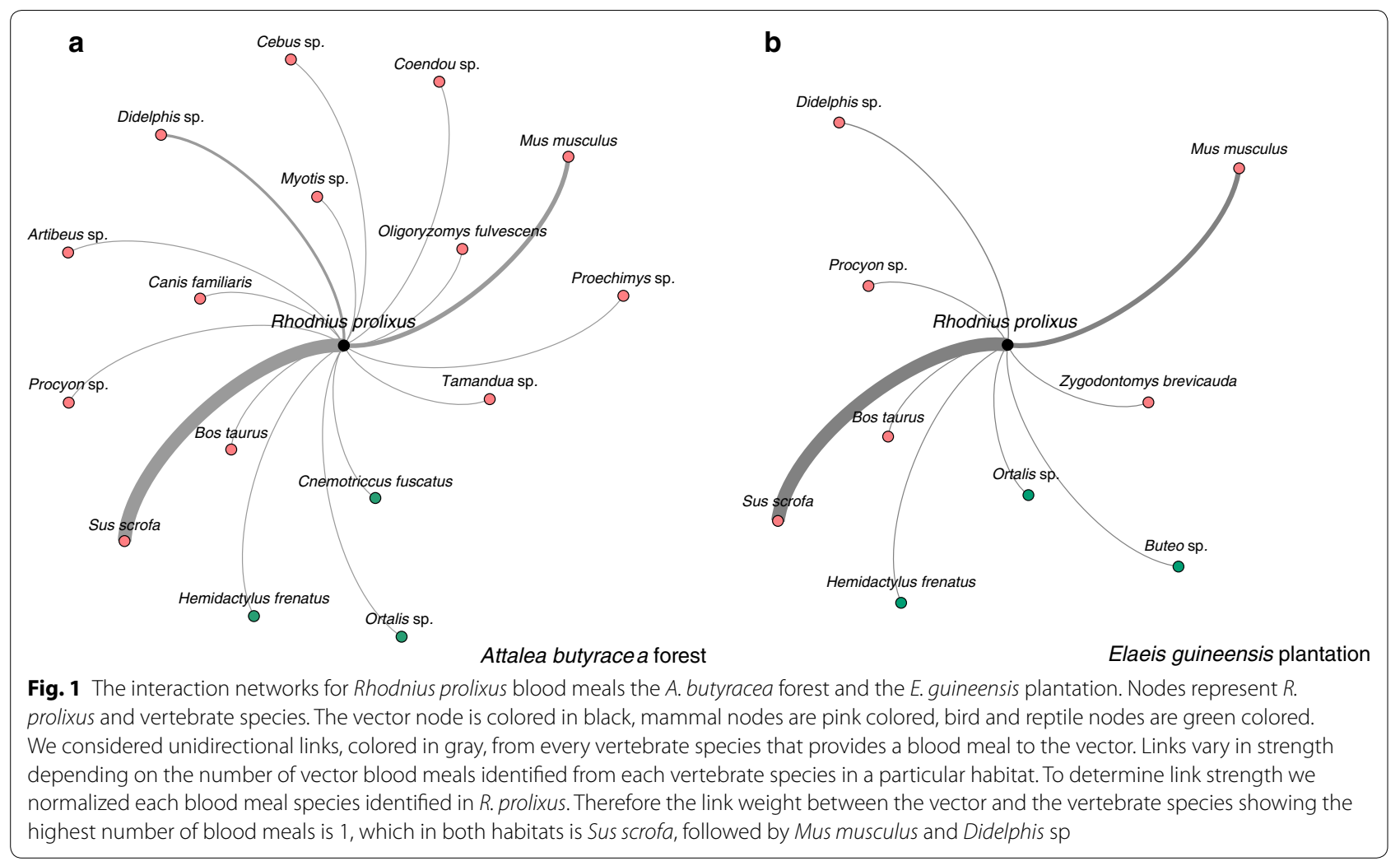

Table 1 Blood meal species detected in R. prolixus individuals collected in the A. butyracea forest

\begin{tabular}{|c|c|c|c|c|c|c|c|}
\hline Class & Order & Species & Reads & $\%$ Reads $^{\mathrm{a}}$ & Blood meals & $\%$ Blood meals & Weight \\
\hline \multirow[t]{2}{*}{ Aves } & Galliformes & Ortalis sp. & 15,946 & 2.11 & 8 & 3.5 & 0.06 \\
\hline & Passeriformes & Cnemotriccus fuscatus & 4125 & 0.55 & 2 & 0.9 & 0.02 \\
\hline Reptilia & Squamata & Hemidactylus frenatus & 9583 & 1.27 & 2 & 0.9 & 0.02 \\
\hline \multirow[t]{14}{*}{ Mammalia } & Artiodactyla & Bostaurus & 963 & 0.13 & 2 & 0.9 & 0.02 \\
\hline & & Sus scrofa & 247,319 & 32.71 & 124 & 54.4 & 1.00 \\
\hline & Carnivora & Canis lupus familiaris & 4073 & 0.54 & 4 & 1.8 & 0.03 \\
\hline & & Procyon sp. & 5391 & 0.71 & 6 & 2.6 & 0.05 \\
\hline & Chiroptera & Artibeus sp. & 6837 & 0.90 & 2 & 0.9 & 0.02 \\
\hline & & Myotis sp. & 75,280 & 9.96 & 9 & 3.9 & 0.07 \\
\hline & Marsupialia & Didelphis sp. & 134,197 & 17.75 & 25 & 11.0 & 0.20 \\
\hline & Primata & Cebus sp. & 195 & 0.03 & 1 & 0.4 & 0.01 \\
\hline & Rodentia & Coendou sp. & 143 & 0.02 & 1 & 0.4 & 0.01 \\
\hline & & Mus musculus & 211,141 & 27.92 & 36 & 15.8 & 0.29 \\
\hline & & Oligoryzomys fulvescens & 25,832 & 3.42 & 2 & 0.9 & 0.02 \\
\hline & & Proechimys sp. & 1602 & 0.21 & 2 & 0.9 & 0.02 \\
\hline & Xenarthra & Tamandua sp. & 13,507 & 1.79 & 2 & 0.9 & 0.02 \\
\hline & & Unassigned & 141,853 & & - & - & - \\
\hline
\end{tabular}

\footnotetext{
${ }^{a}$ Percentage after removing unassigned reads
} 
Table 2 Blood meal species detected in R. prolixus individuals collected in the E. guineensis plantation

\begin{tabular}{|c|c|c|c|c|c|c|c|}
\hline Class & Order & Species & Reads & $\%$ Reads $^{\mathrm{a}}$ & Blood meals & \% Blood meals & Weight \\
\hline \multirow[t]{2}{*}{ Aves } & Accipitriformes & Buteo sp. & 2543 & 0.58 & 1 & 0.5 & 0.01 \\
\hline & Galliformes & Ortalis sp. & 1391 & 0.32 & 3 & 1.6 & 0.02 \\
\hline Reptilia & Squamata & Hemidactylus frenatus & 6042 & 1.37 & 1 & 0.5 & 0.01 \\
\hline \multirow[t]{7}{*}{ Mammalia } & Artiodactyla & Bostaurus & 674 & 0.15 & 1 & 0.5 & 0.01 \\
\hline & & Sus scrofa & 232,321 & 52.70 & 121 & 65.1 & 1.00 \\
\hline & Carnivora & Procyon sp. & 1176 & 0.27 & 2 & 1.1 & 0.02 \\
\hline & Marsupialia & Didelphis sp. & 33032 & 7.49 & 11 & 5.9 & 0.09 \\
\hline & Rodentia & Mus musculus & 160304 & 36.37 & 45 & 24.2 & 0.37 \\
\hline & & Zygodontomys brevicauda & 3313 & 0.75 & 1 & 0.5 & 0.01 \\
\hline & & Unassigned & 133615 & - & - & - & - \\
\hline
\end{tabular}

a Percentage after removing unassigned reads

Table 3 Percentage (number) of blood meal species identified per vector discriminated by stage and habitat

\begin{tabular}{|c|c|c|c|c|c|c|c|c|c|c|}
\hline \multirow[t]{2}{*}{ Stage } & \multicolumn{5}{|c|}{ Attalea butyracea forest } & \multicolumn{5}{|c|}{ Elaeis guineensis plantation } \\
\hline & 0 & 1 & 2 & 3 & Total & 0 & 1 & 2 & 3 & Total \\
\hline N1 & 0 & $0.6(2)$ & $0.3(1)$ & 0 & $0.9(3)$ & 0 & $0.6(2)$ & $0.3(1)$ & 0 & $0.9(3)$ \\
\hline N2 & $0.3(1)$ & $4.4(14)$ & $1.9(6)$ & 0 & $6.6(21)$ & $0.3(1)$ & $4.4(14)$ & $0.6(2)$ & 0 & $5.4(17)$ \\
\hline N3 & $0.6(2)$ & $7.9(25)$ & $2.2(7)$ & $1.3(4)$ & $12(38)$ & $0.9(3)$ & $10.1(32)$ & $4.7(15)$ & $0.6(2)$ & $16.5(52)$ \\
\hline N4 & $0.3(1)$ & $5.7(18)$ & $4.7(15)$ & $0.3(1)$ & $11.1(35)$ & $0.9(3)$ & $7.9(25)$ & $10.1(15)$ & $0.3(1)$ & $13.9(44)$ \\
\hline N5 & $0.9(3)$ & $14.9(47)$ & $4.4(14)$ & $2.2(7)$ & $22.5(71)$ & $0.9(3)$ & $6.6(21)$ & $2.5(8)$ & 0 & $10.1(32)$ \\
\hline Total & $2.2(7)$ & $33.5(106)$ & $13.6(43)$ & $3.8(12)$ & $53.2(168)$ & $3.2(10)$ & $29.7(94)$ & $13(41)$ & $0.3(1)$ & $46.8(148)$ \\
\hline
\end{tabular}

sp.). The highest infection was predicted for individuals feeding only from generalist or opportunistic mammal species: opossum, raccoon (Procyon sp.), house mouse, and the generalist rodents, Oligoryzomys fulvescens and Zygodontomys brevicauda. For individuals feeding from domestic and generalist mammals, the regression tree predicted an infection rate of $76 \%$. We did not find vectors feeding from both domestic and sylvatic species.

The general linear model showed no significant effect of S. scrofa, Didelphis sp., nor M. musculus blood meals on vector $T$. cruzi infection. In this analysis we considered single, dual, and triple blood meals that detected these species. The Pearson's correlation test showed no relation between host body size and vector infection for the study site $(r=0.0018, P=0.97)$, forest $(r=-0.1302$, $P=0.13)$, or plantation $(r=0.1080 P=0.18)$.

\section{Blood meals spatial patterns}

Few species identified in the blood meals had significant Moran's $I$ indices different from zero $(P<0.1)$, implying that a great majority of blood meals were randomly distributed in the study site. We found positive significant $I$ indices for Ortalis sp. $(I=0.09, P<0.05)$, Proechimys
( $I=0.03, P=0.004)$, Artibeus sp. $(I=0.09, P<0.05)$, and Canis lupus familiaris $(I=0.02, P=0.07)$, thus these species blood meals displayed a clustering pattern (Fig. 3).

\section{Discussion}

Palm trees are the natural ecotope of most Rhodnius species [39] because they provide refuge and plenty of food sources, as many vertebrate species forage there [64-66]. Attalea butyracea is a complex-crown palm tree that is ubiquitous in the Orinoco region, where large $R$. prolixus densities with high $T$. cruzi natural infection rates [67-69] and blood meals from all terrestrial vertebrate taxa, except amphibians, have been reported [70]. In this study, we present a detailed description and analysis of $R$. prolixus blood meals in $A$. butyracea palms and oil palms (E. guineensis) in the department of Casanare, Colombia.

Oil palm plantations have been suggested as a new ecotope for $R$. prolixus and T. cruzi maintenance [40]. Here, our findings suggest that E. guineensis palm trees could be providing $R$. prolixus and T. cruzi a habitat of similar quality to $A$. butyracea palm trees located in disturbed landscapes. In both habitats, vertebrate species identified from $R$. prolixus blood meals are similar, with minor 


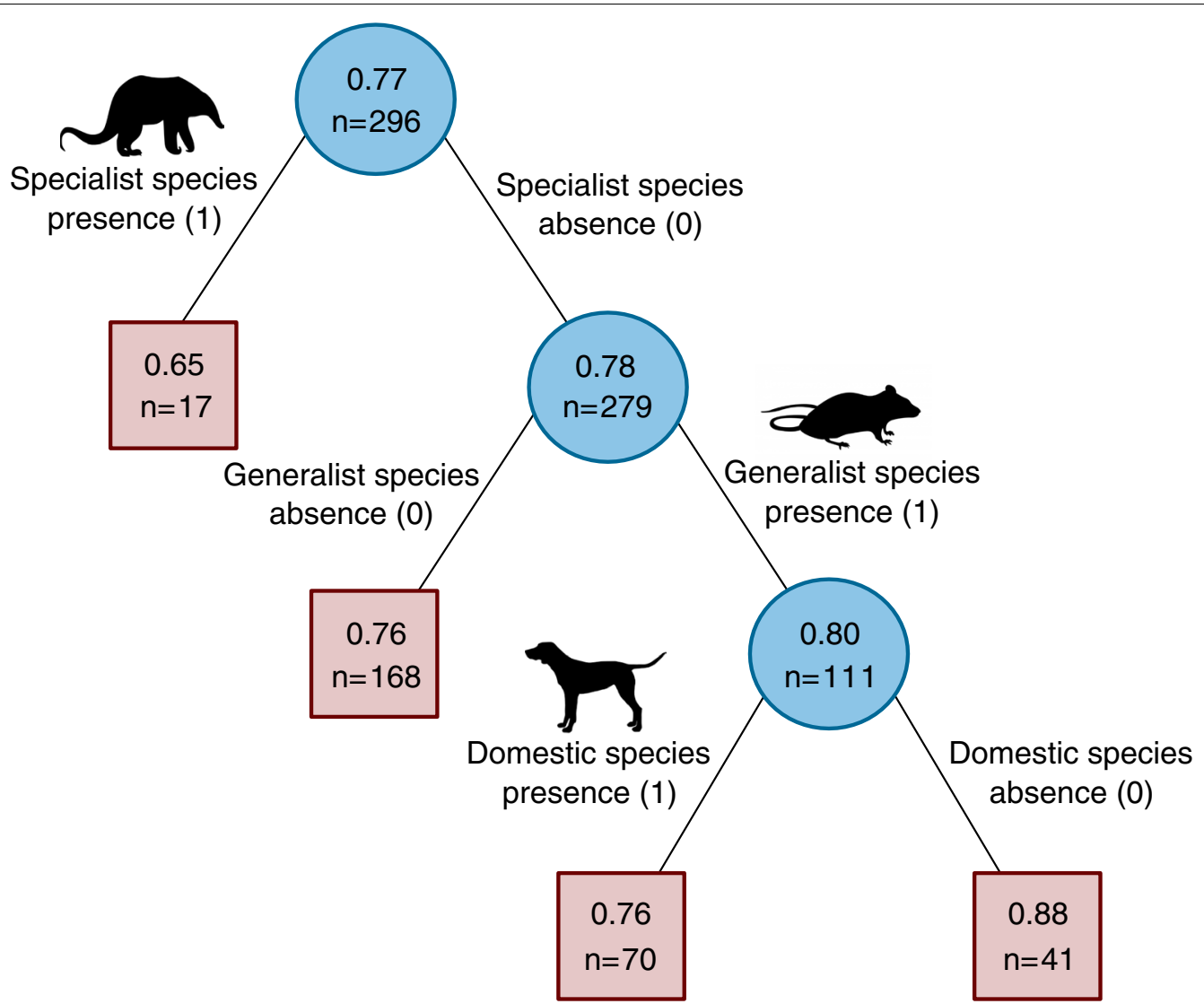

Fig. 2 Regression tree analysis for vector infection. To test the relationship between vector infection prevalence and host species habitat associations we used a regression tree model. We considered domestic, generalist, and specialist sylvatic as habitat associations. Circles and rectangles represent non-terminal and terminal nodes, respectively. The circled node at the top is labeled with the number of infected individuals $(n=296)$ and total $R$. prolixus infection rate variance explained by the tree (77\%). Links between nodes are labeled with the presence (1) or absence (0) of a species-habitat association. All nodes are labeled with the predicted infection rate and the number of individuals that meet the preceding link(s) condition(s). The highest infection rate, 88\%, was predicted for $R$. prolixus feeding solely from generalist mammal species. On the other hand, the lowest infection rate (64\%) was predicted for individuals having blood meals only from specialist mammal species

differences in composition, providing a comparable enzoonotic scenario.

The Orinoco region is known as a high transmission area for Chagas disease. Reports showed a T. cruzi natural infection between $60-85 \%[68,69]$ and a palm infestation index reaching 100\% [71]. Here we showed high infection rates, comparable to previous studies, $76 \%$ in the A. butyracea palm trees and $75 \%$ in the E. guineensis plantation. Therefore, our finding that $95.6 \%$ of vector blood meals corresponded to mammalian hosts could be a possible explanation for such a high vector infection, because mammals are the only competent reservoirs for $T$. cruzi infection. The remaining blood meals were identified as coming from birds and geckos which are known to be refractory to $T$. cruzi infection $[72,73]$.

In this study, the domestic pig was the top ranked blood meal in both habitats, which was initially surprising, but is supported by the presence of a pigpen in the
A. butyracea area. In addition, Sus scrofa domestica has been suggested as an attractive host species [74, 75]. Nonetheless, the spatial analysis on vectors displaying pig blood meal did not show a clustering pattern; instead these vectors were randomly distributed, probably because the pigpen is less than 200 meters far from the remotest palm tree in the forest. The spatial pattern of pig blood meals in the plantation could be attributable to the occasional release of pigs within the habitat area. Thus, our findings suggests that in this area, the pig could be a relevant food source for $R$. prolixus.

Regression tree analysis showed that generalist or opportunistic host species could be playing an important role in T. cruzi maintenance in the area. Habitat-generalist species are known for their synanthropic behavior, because they benefit from living in close proximity to humans. Thus, these species provide food source for triatomines in disturbed landscapes and are parasite 


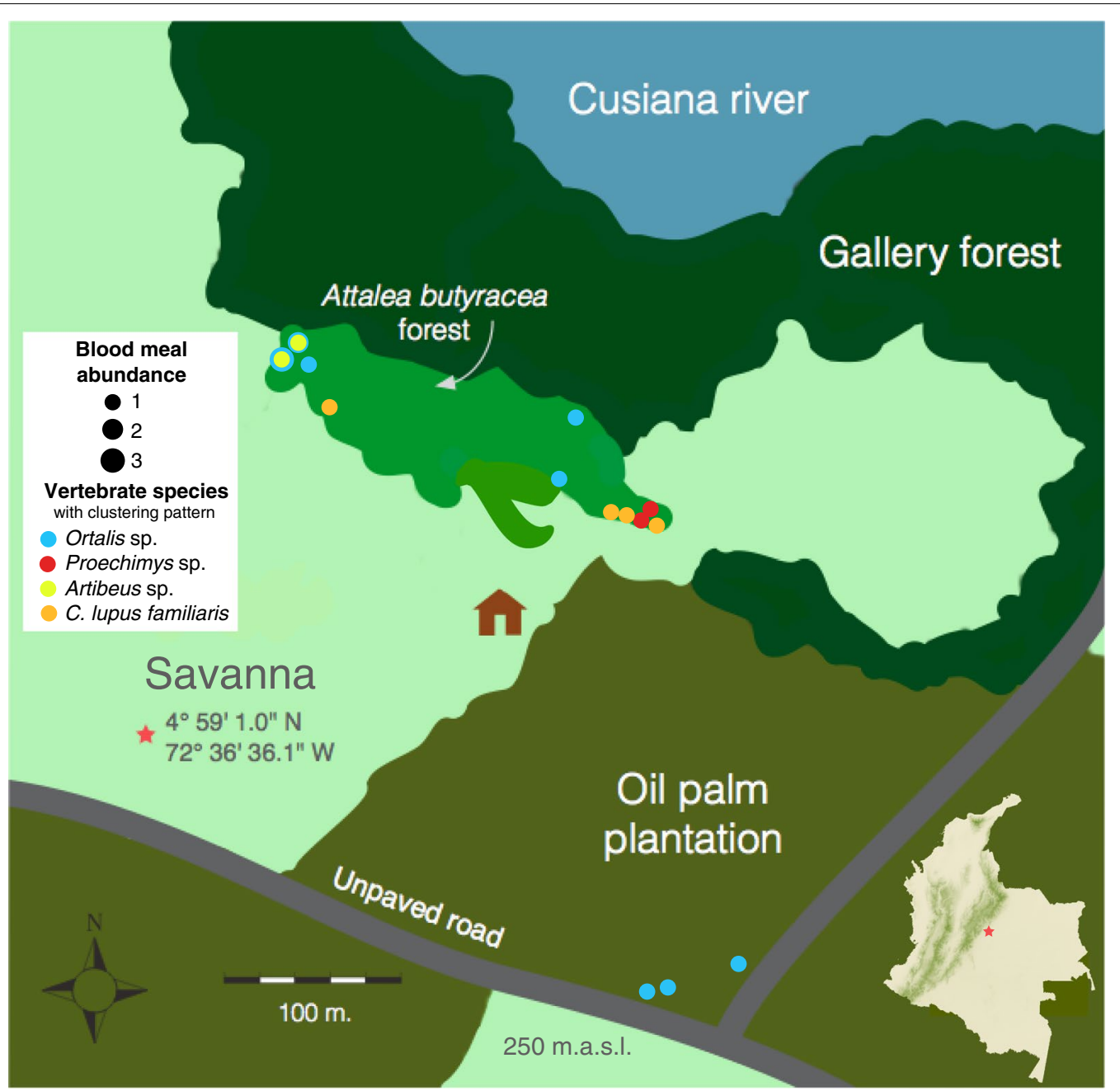

Fig. 3 Spatial distribution of clustered vector blood meals. Los Potrillos, Tauramena is located in the department of Casanare (Orinoco region, Colombia). The study site is adjacent to the Cusiana River and covers an area of 25 ha that comprehends savanna, A. butyracea forest, gallery forest, and oil palm plantation landscapes. Additionally, peridomestic areas are present. Vectors were collected in A. butyracea and E. guineensis palms. Based on Moran's / index computed for the abundance of blood meal species identified in R. prolixus, most blood meals were randomly distributed in the study area. The few species that exhibited clustering were Ortalis sp. (blue), Proechimys sp. (red), Artibeus sp (yellow), and C. lupus familiaris (orange)

reservoirs $[23,75]$. Generalist rodents were detected in vector blood meals from both habitats and $M$. musculus was the predominant species. Mus musculus is an introduced Muridae species that has adapted to domestic and peridomestic habitats in many regions of Colombia [76], and its role as a T. cruzi competent reservoir needs to be tested. In a previous study, we found that 1 out of 12 individuals infected (8.3\%) (unpublished data, Casanare, Colombia) and in Mexico 6.2\% were T. cruzipositive [77]. The common opossum, D. marsupialis, a well-known T. cruzi reservoir [22], showed an infection of $29 \%$ in this site (unpublished data), and comprised a significant proportion of vector blood meals in the $A$. butyracea forest and to a lesser extent, the E. guineensis plantation. Other identified generalist species were the crab-eating raccoon (Procyon sp.) and the rodents O. fulvescens and $Z$. brevicauda.

Blood meals from specialist species were absent in the oil palm plantation and present in a few bugs captured in the A. butyracea forest (7.5\%), which is expected considering that the entire study site is particularly altered. Since specialist species tend to be more K-selected (lower reproductive rates and longer life spans) compared to opportunistic species [78], high vector infection rates in the area could also be explained by the little presence of these species in $R$. prolixus blood meals $[33,79]$. 
We exclusively analyzed nymphs and therefore were expecting to identify mostly arboreal or scansorial vertebrate species. However, we found terrestrial species in nymph blood meals. This observation was also reported by Gottdenker et al. [33], where dog, pig, and cow were identified in vector blood meals. To our knowledge, these results could suggest two possibilities that are not mutually exclusive. Nymphs might be descending to the ground to feed and return to the palm trees, as suggested by previous reports highlighting the considerable power of triatomine dispersal [80]. Both $R$. prolixus nymphs and adults seem to migrate from their colonies to other sites by crawling [81] and/or passive-dispersal mechanisms, such as bugs clinging to birds [82]. The other possibility is that nymphs could be feeding from engorged adults who have fed from a terrestrial mammal before. This phenomenon known as hematoklepty [83-86] is also supported by multiple blood meals detection in first and second nymphal stage individuals in the present and a previous study [45]. However, recent reports suggest that thermal stimulation is the only cue triggering bites to conspecifics in $R$. prolixus and kissing bugs thermoregulate even when feeding on vertebrates [87]. Thus, the mechanism(s) explaining how early stage triatomines that are palmassociated feed from terrestrial species requires further study.

Previous reports in Colombia have detected vertebrate species in triatomine blood meals using ELISA and the cytochrome $b$ gene PCR-HRM (polymerase chain reaction - high resolution melting); however, these studies identified fewer species than our study and higher taxonomic levels of sylvatic animals were not specified (bats and mice) [70, 88, 89]. For the ELISA approach, the fact that some species-specific anti-sera might not be available, could lead to unidentified species [88]. On the other hand, PCR-HRM protocol is available only for some species, which implies further standardization and required sequencing for not available species. Based on our results, we highly recommend using next-generation sequencing (NGS) method, which is an affordable and accurate method for identifying multiple triatomine blood meals in a single individual [45]. Detecting additional vertebrate species in vector blood meals besides easily identifiable species could help target novel host species and allow for a better understanding of triatomine ecology. This is particularly important, considering how land-use change may result in a host preference or availability switch [90, 91].

In this study, all processed nymphs were engorged at the time of collection, though chicken reads were present in a considerable number of samples, We do not discard the possibility of vectors feeding from chickens, which were highly present in the study site; however, given the study purposes, baited live traps with chickens could be a confounding element.

On the other hand, we obtained $18.7 \%$ of unassigned reads, suggesting gaps in the reference material. Currently, the Orinoco region still lacks biodiversity data for their species description and genetic database, partially due to previous inaccessibility to natural ecosystems as result of safety and security measures in this conflict-prone zone [92]. Finally, research on reservoir competence regarding the identified mammal species is necessary to fully understand T. cruzi enzoonotic transmission cycle in these habitats.

\section{Conclusions}

We conclude that generalist host species, rather than specialist, could be driving high vector infection rates with $T$. cruzi in oil palm plantations in the study area. Additionally, we suggest that oil palm plantations in the Orinoco region could serve as an extension of highly altered habitats with $A$. butyracea palms in terms of reservoir host movement and T. cruzi transmission. This could be the case for E. guineensis plantations near highly intervened areas, such as peridomicile and cattle pasture. Nonetheless, further research is required to understand parasite transmission scenarios in plantations with different spatial configurations in relation to peridomicile and other habitats.

\section{Additional files}

Additional file 1: Figure S1. Map of the study site. Triatomines were collected an Attalea butyracea forest (2 ha) and an oil palm plantation (11 ha). Black dots represent baited live traps locations in both habitats. Table S1. Data from mammal species found in vector blood meals, which were used for the statistical analyses.

Additional file 2. 12S DNA reference database of vertebrate species from GenBank.

Additional file 3. 12S DNA taxonomy file of vertebrate species from GenBank.

\begin{abstract}
Abbreviations
ANLA: Agencia Nacional de Licencias Ambientales-National Authority of Environmental Licenses; DTU: discrete taxonomic unit; ELISA: enzyme-linked immunosorbent assay; LUC: land use change; N1: first nymphal stage; N2: second nymphal stage; N3: third nymphal stage; N4: fourth nymphal stage; N5: fifth nymphal stage; NGS: next-generation sequencing; OTU: operational taxonomic unit; PCR: polymerase chain reaction; PCR-HRM: polymerase chain reaction-high resolution melting.
\end{abstract}

\section{Acknowledgements}

We thank Norma Forero, Germán Aguilera, Carlos Bravo, Luisa Rodríguez, and Nazario Rivera, for the help during fieldwork, and Cielo M. León who contributed with laboratory procedures.

\section{Authors' contributions}

DE and JDU carried out the field work and molecular laboratory work. MC carried out molecular work. DE and TJK carried out sequence alignments. 
DE carried out the statistical analyses. NLG and TCG participated in the study design. CG, FG, and JC designed and coordinated the study. All authors contributed to drafting the manuscript. All authors read and approved the final manuscript.

\section{Funding}

This work was supported by the Vice-president for research at Universidad de los Andes and Colciencias call 617 (2013).

\section{Availability of data and materials}

Data supporting the conclusions of this article are included within the article and its additional files.

\section{Ethics approval and consent to participate}

Sampling procedures were done under Universidad de Los Andes collection approval (Resolution 1177 October 9th 2014-IDB 0359) from the National Authority of Environmental Licenses (ANLA) and the ethical review board of the Universidad de los Andes (CICUAL-C.FUA 14-026).

\section{Consent for publication}

Not applicable.

\section{Competing interests}

The authors declare that they have no competing interests.

\section{Author details}

' Grupo de Investigación en Biología Matemática y Computacional (BIOMAC), Universidad de los Andes, Bogota, Colombia. ${ }^{2}$ Department of Pathology, School of Veterinary Medicine, The University of Georgia, Athens, GA, USA. ${ }^{3}$ Centro de Investigaciones en Microbiología y Parasitología Tropical (CIMPAT), Facultad de Ciencias, Universidad de los Andes, Bogotá, Colombia. ${ }^{4}$ Grupo de Investigación en Ingeniería Biomédica (GIB), Universidad de los Andes, Bogota, Colombia. ${ }^{5}$ Department of Environmental Health Science, College of Public Health, University of Georgia, Athens, GA, USA.

Received: 22 December 2018 Accepted: 20 May 2019

Published online: 28 May 2019

\section{References}

1. Newbold T, Hudson LN, Phillips HRP, Hill SLL, Contu S, Lysenko I, et al. A global model of the response of tropical and sub-tropical forest biodiversity to anthropogenic pressures. Proc R Soc B Biol Sci. 2014;281:20141371.

2. Davies KF, Margules CR, Lawrence JF. Which traits of species predict population declines in experimental forest fragments? Ecology. 2000;81:1450-61.

3. Henle K, Davies KF, Kleyer M, Margules C, Settele J. Predictors of species sensitivity to fragmentation. Biodivers Conserv. 2004;13:207-51.

4. Ewers RM, Didham RK. Confounding factors in the detection of species responses to habitat fragmentation. Biol Rev Camb Philos Soc. 2006:81:117-42.

5. Barbaro L, Van Halder I. Linking bird, carabid beetle and butterfly lifehistory traits to habitat fragmentation in mosaic landscapes. Ecography. 2009;32:321-33

6. Barragán F, Moreno CE, Escobar F, Halffter G, Navarrete D. Negative impacts of human land use on dung beetle functional diversity. PLoS ONE. 2011;6:e17976.

7. Vetter D, Hansbauer MM, Végvári Z, Storch I. Predictors of forest fragmentation sensitivity in Neotropical vertebrates: A quantitative review. Ecography. 2011;34:1-8.

8. Newbold T, Scharlemann JPW, Butchart SHM, Sekercioğlu CH, Alkemade $\mathrm{R}$, Booth $\mathrm{H}$, et al. Ecological traits affect the response of tropical forest bird species to land-use intensity. Proc Biol Sci. 2013;280:20122131.

9. Levins R. Evolution in changing environments. Some theoretical explorations. Princeton: Princeton University Press; 1968.

10. Futuyma DJ, Moreno G. The evolution of ecological specialization. Annu Rev Ecol Syst. 1988;19:207-33.

11. Kassen R. The experimental evolution of specialists, generalists, and the maintenance of diversity. J Evol Biol. 2002;173-90.
12. Marvier M, Kareiva P, Neubert MG. Habitat destruction, fragmentation, and disturbance promote invasion by habitat generalists in a multispecies metapopulation. Risk Anal. 2004;24:869-78.

13. Östergård $H$, Ehrlén J. Among population variation in specialist and generalist seed predation - The importance of host plant distribution, alternative hosts and environmental variation. Oikos. 2005;111:39-46.

14. Devictor $V$, Julliard $R$, Jiguet F. Distribution of specialist and generalist species along spatial gradients of habitat disturbance and fragmentation. Oikos. 2008;117:507-14

15. Gibson L, Lee TM, Koh LP, Brook BW, Gardner TA, Barlow J, et al. Primary forests are irreplaceable for sustaining tropical biodiversity. Nature. 2011:478:378-81.

16. Carrara E, Arroyo-Rodríguez V, Vega-Rivera JH, Schondube JE, de Freitas SM, Fahrig L. Impact of landscape composition and configuration on forest specialist and generalist bird species in the fragmented Lacandona rainforest, Mexico. Biol Conserv. 2015;184:117-26.

17. Daily GC, Ceballos G, Pacheco J, Suzán G, Sánchez-Azofeifa A. Countryside biogeography of Neotropical mammals: conservation opportunities in agricultural landscapes of Costa Rica. Conserv Biol. 2003;17:1814-26.

18. Yahnke CJ, Meserve PL, KsiazekTG, Mills JN. Patterns of infection with Laguna Negra virus in wild populations of Calomys laucha in the central Paraguayan Chaco. Am J Trop Med Hyg. 2001;65:768-76.

19. Utrera A, Duno G, Ellis BA, Salas RA, de Manzione N, Fulhorst CF, et al. Small mammals in agriculturalareas of the western llanos of Venezuela: community structure, habitat associations, and relative densities. J Mammal. 2000;81:536-48.

20. Litvaitis JA, Villafuerte R. Intraguild predation, mesopredator release, and prey stability. Conserv Biol. 1996;10:676-7.

21. Crooks KR, Soulé ME. Mesopredator release and avifaunal extinctions in a fragmented system. Nature. 1999;400:563-6.

22. Travi BL, Jaramillo C, Montoya J, Segura I, Zea A, Goncalves A, Velez ID. Didelphis marsupialis, an important reservoir of Trypanosoma (Schizotrypanum) cruzi and Leishmania (Leishmania) chagasi in Colombia. Am J Trop Med Hyg. 1994;50:557-65.

23. Herrera L, Urdaneta-Morales S. Synanthropic rodent reservoirs of Trypanosoma (Schizotrypanum) cruzi in the valley of Caracas, Venezuela. Rev Inst Med Trop Sao Paulo. 1997;39:279-82.

24. Castellaw AH, Chenney EF, Varela-Stokes AS. Tick-borne disease agents in various wildlife from Mississippi. Vector-Borne Zoonotic Dis. 2011;11:439-42.

25. Bern C, Kjos S, Yabsley MJ, Montgomery SP. Trypanosoma cruzi and Chagas' disease in the United States. Clin Microbiol Rev. 2011;24:655-81.

26. Prange S, Gehrt SD, Wiggers EP. Demographic factors contributing to high raccoon densities in urban landscapes. J Wildl Manage. 2003;67:324-33.

27. Bino G, Dolev A, Yosha D, Guter A, King R, Saltz D, et al. Abrupt spatial and numerical responses of overabundant foxes to a reduction in anthropogenic resources. J Appl Ecol. 2010;47:1262-71.

28. Martin LB, Weil ZM, Kuhlman JR, Nelson RJ. Trade-offs within the immune systems of female White-footed Mice. Peromyscus leucopus. Funct Ecol. 2006;20:630-6.

29. Lee KA. Linking immune defenses and life history at the levels of the individual and the species. Integr Comp Biol. 2006:46:1000-15.

30. Lee KA, Wikelski M, Robinson WD, Robinson TR, Klasing KC. Constitutive immune defences correlate with life-history variables in tropical birds. J Anim Ecol. 2008;77:356-63.

31. Egoscue $\mathrm{H}$. Flea exchange between deer mice and some associated small mammals in western Utah. Gt Basin Nat. 1976:36:475-80.

32. Becker DJ, Streicker DG, Altizer S. Using host species traits to understand the consequences of resource provisioning for host-parasite interactions. J Anim Ecol. 2018;87:511-25.

33. Gottdenker NL, Chaves LF, Calzada JE, Saldaña A, Carroll CR. Host life history strategy, species diversity, and habitat influence Trypanosoma cruzi vector infection in changing landscapes. PLoS Negl Trop Dis. 2012;6:5-7.

34. Pérez-Molina JA, Molina I. Chagas disease. Lancet. 2018;391:82-94.

35. Jansen AM, Roque ALR. Domestic and wild mammalian reservoirs. In: Telleria J, Tibayrenc M, editors. American trypanosomiasis, Chagas disease - one hundred years of research. London: Elsevier; 2010. p. 249-76. 
36. Gottdenker NL, Streicker DG, Faust CL, Carroll CR. Anthropogenic land use change and infectious diseases: a review of the evidence. EcoHealth. 2014;11:619-32.

37. Pardo L, Payan E. Mamiferos de un agropaisaje de palma de aceite en las sabanas inundables de Orocue, Casanare, Colombia. Biota Colomb. 2015;16:54-66.

38. Abad-Franch F, Monteiro FA, Jaramillo ON, Gurgel-Goncalves R, Dias FBS, Diotaiuti L. Ecology, evolution, and the long-term surveillance of vectorborne Chagas disease: a multi-scale appraisal of the tribe Rhodniini (Triatominae). Acta Trop. 2009;1 10:159-77.

39. Abad-Franch F, Lima MM, Sarquis O, Gurgel-Gonçalves R, Sánchez-Martín M, Calzada J, et al. On palms, bugs, and Chagas disease in the Americas. Acta Trop. 2015;151:126-41.

40. Guhl F, Pinto N, Marín D, Herrera C, Aguilera G, Naranjo J, et al. Primer reporte de Rhodnius prolixus Stal, en Elaeis guineensis variedad Papúa, en plantaciones agroindustriales de Villanueva, Casanare. Biomedica. 2005;25:158-9.

41. Carter C, Finley W, Fry J, Jackson D, Willis L. Palm oil markets and future supply. Eur J Lipid Sci Technol. 2007;109:307-14.

42. Castiblanco C, Etter A, Aide TM. Oil palm plantations in Colombia: a model of future expansion. Environ Sci Policy. 2013;27:172-83.

43. Minorta-Cely V, Rangel-Churio JO. El clima de la Orinoquia colombiana. In: Colombia EEUN Editors. Colombia Diversidad Biótica XIV. La Región De La Orinoquia De Colombia; 2014. p. 153-206.

44. Angulo VM, Esteban L. Nueva trampa para la captura de triatominos en hábitats silvestres y peridomésticos. Biomedica. 2011;31:264-8.

45. Kieran TJ, Gottdenker NL, Varian CP, Saldaña A, Means N, Owens D, et al. Blood meal source characterization using Illumina sequencing in the Chagas disease vector Rhodnius pallescens (Hemiptera: Reduviidae) in Panamá. J Med Entomol. 2017:54:1786-9.

46. Britto C, Cardoso MA, Vanni CM, Hasslocher-Moreno A, Xavier SS, Oelemann W, et al. Polymerase chain reaction detection of Trypanosoma cruzi in human blood samples as a tool for diagnosis and treatment evaluation. Parasitology. 1995;110(Suppl. 3):241-7.

47. Ramírez JD, Guhl F, Rendón LM, Rosas F, Marin-Neto JA, Morillo CA. Chagas cardiomyopathy manifestations and Trypanosoma cruzi genotypes circulating in chronic chagasic patients. PLoS Negl Trop Dis. 2010;4:e899.

48. Humair P-F, Douet W, Cadenas FMM, Schouls LM, Van de Pol I, Gern L, et al. Molecular identification of bloodmeal source in Ixodes ricinus ticks using 12S rDNA as a genetic marker. J Med Entomol. 2007:44:869-80.

49. Glenn TC, Nilsen R, Kieran TJ, Finger JW, Pierson TW, Bentley KE, et al. Adapterama I. Universal stubs and primers for thousands of dual-indexed Illumina libraries (iTru \&amp; iNext). BioRxiv. 2016. p. 049114.

50. Caporaso JG, Kuczynski J, Stombaugh J, Bittinger K, Bushman FD, Costello EK, et al. QIIME allows analysis of high-throughput community sequencing data. Nat Methods. 2010;7:335-6.

51. Solari S, Muñoz-Saba Y, Rodríguez-Mahecha JV, Defler TR, Ramírez-Chaves HE, Trujillo F. Riqueza, endemismo y conservación de los mamíferos de Colombia. Mastozool Neotrop. 2013;20:301-65.

52. Angarita- Sierra T, Ospina-Sarria J, Anganoy-Criollo M, Pedroza-Banda R, Lynch JD. Guía de campo de los Anfibios y Reptiles del departamento de Casanare (Colombia). In: YOLUKA ONG, Fundación de Investigación en Biodiversidad y Conservación. Serie Biodiversidad para la Sociedad No. 2. Universidad Nacional de Colombia. Sede Orinoquia; 2013.

53. Acevedo-Charry OA, Pinto-Gómez A, Rangel-Ch O. Birds of the Orinoquian region of Colombia: a review on its records. Colomb Divers Biot. 2014;14:691-750.

54. The IUCN Red List of Threatened Species. 2018. http://www.iucnredlis t.org. Accessed Jan 2018.

55. Saiki R, Gelfand D, Stoffel S, Scharf S, Higuchi R, Horn G, et al. Primerdirected enzymatic amplification of DNA with a thermostable DNA polymerase. Science. 1988;239:487-91.

56. Zazzi M, Romano L, Catucci M, De Milito A, Almi P, Gonnelli A, et al. Low human immunodeficiency virus type 1 (HIV-1) DNA burden as a major cause for failure to detect HIV-1 DNA in clinical specimens by PCR. J Clin Microbiol. 1995:33:205-8.

57. González C, León C, Paz A, López M, Molina G, Toro D, et al. Diversity patterns, Leishmania DNA detection, and bloodmeal identification of Phlebotominae sand flies in villages in northern Colombia. PLoS ONE. 2018;13:e0190686.
58. West GB, Brown JH, Enquist BJ. The fourth dimension of life: fractal geometry and allometric scaling of organisms. Science. 1999;284:1677-9.

59. The Animal Diversity Web. 2018. http://animaldiversity.org. Accessed Jan 2018.

60. Bastian M, Heymann S, Jacomy M. Gephi: An open source software for exploring and manipulating networks. Third International AAAI Conference on weblogs and social media, San Jose, California; 2009. p. 361-2.

61. R Development Core Team. R: A language and environment for statistical computing. Vienna: R Foundation for Statistical Computing; 2016. https:// www.R-project.org/.

62. Breiman L, Friedman JH, Olshen RA, Stone CJ. Classification and regression trees. Vol. 19; 1984.

63. Paradis E, Claude J, Strimmer K. APE: analyses of phylogenetics and evolution in R language. Bioinformatics. 2004;20:289-90.

64. Teixeira ARL, Monteiro PS, Rebelo JM, Argañaraz ER, Vieira D, Lauria-Pires L, et al. Emerging chagas disease: trophic network and cycle of transmission of Trypanosoma cruzi from palm trees in the Amazon. Emerg Infect Dis. 2001;7:100-12.

65. Zeledón R, Marín F, Calvo N, Lugo E, Valle S. Distribution and ecological aspects of Rhodnius pallescens in Costa Rica and Nicaragua and their epidemiological implications. Mem Inst Oswaldo Cruz. 2006;101:75-9.

66. Gurgel-Gonçalves R, Cura C, Schijman AG, Cuba CAC. Infestation of Mauritia flexuosa palms by triatomines (Hemiptera: Reduviidae), vectors of Trypanosoma cruzi and Trypanosoma rangeli in the Brazilian savanna. Acta Trop. 2012;121:105-11.

67. Angulo VM, Esteban L, Luna KP. Attalea butyracea próximas a las viviendas como posible fuente de infestación domiciliaria por Rhodnius prolixus (Hemiptera: Reduviidae) en los Llanos Orientales de Colombia. Biomedica. 2012;32:277-85.

68. Urbano P, Poveda C, Molina J. Effect of the physiognomy of Attalea butyracea (Arecoideae) on population density and age distribution of Rhodnius prolixus (Triatominae). Parasit Vectors. 2015;8:1-12.

69. Rendón LM, Guhl F, Cordovez JM, Erazo D. New scenarios of Trypanosoma cruzi transmission in the Orinoco region of Colombia. Mem Inst Oswaldo Cruz. 2015;110:283-8

70. Angulo-Silva VM, Castellanos-Domínguez YZ, Flórez-Martínez M, EstebanAdarme L, Pérez-Mancipe W, Farfán-García AE, et al. Human trypanosomiasis in the eastern plains of Colombia: new transmission scenario. Am J Trop Med Hyg. 2016;94:348-51.

71. Pinto N, Marín D, Herrera C, Vallejo G, Naranjo J, Guhl F. Comprobación del ciclo selvático de Rhodnius prolixus Stal en reductos de Attalea butyracea en el departamento de Casanare. Biomedica. 2005;25:159.

72. Minter-Goedbloed E, A. B. Croon JJ. The insusceptibility of chickens to Trypanosoma (Schizotrypanum) cruzi. Trans R Soc Trop Med Hyg. 1981;75:350-3.

73. Lima MF, Kierszenbaum F. Lysis of vector-transmissible, metacyclic forms of Trypanosoma cruzi by avian serum. J Parasitol. 1984;70:155-6.

74. Valente VC, Valente SAS, Noireau F, Carrasco HJ, Miles MA. Chagas disease in the Amazon basin: association of Panstrongylus geniculatus (Hemiptera: Reduviidae) with domestic pigs. J Med Entomol. 1998;35:99-103.

75. Noireau F, Diosque P, Jansen AM. Trypanosoma cruzi: adaptation to its vectors and its hosts. Vet Res. 2009;40(Suppl. 2):26.

76. Ramírez-Chaves H, Ortega-Rincón M, Pérez WA, Marín D. Historia de las especies de mamíferos exóticos en Colombia. Boletín Científico del Mus Hist Nat. 2011;15:139-56.

77. Ramsey JM, Gutiérrez-Cabrera AE, Salgado-Ramírez L, Peterson AT, Sánchez-Cordero V, Ibarra-Cerdeña CN. Ecological connectivity of Trypanosoma cruzi reservoirs and Triatoma pallidipennis hosts in an anthropogenic landscape with endemic Chagas disease. PLoS ONE. 2012;7:e46013.

78. MacArthur R. On the relative abundance of species. Am Nat. 1960;94:25-36.

79. Johnson PTJ, Rohr JR, Hoverman JT, Kellermanns E, Bowerman J, Lunde $\mathrm{KB}$, et al. Living fast and dying of infection: host life history drives interspecific variation in infection and disease risk. Ecol Lett. 2012;15:235-42.

80. Forattini OP. Chagas' disease and human behaviour. In: Demography and vector-borne disease. Boca Raton: CRC Press; 1989. p. 107-20.

81. Zeledón R, Rabinovich JE. Chagas' disease: an ecological appraisal with special emphasis on its insect vectors. Annu Rev Entomol. 1981;26:101-33.

82. Gamboa C. Dispersión de Rhodnius prolixus en Venezuela. Bol Dir Malariol San Amb. 1962;3:262. 
83. Ryckman R. Recent observations of cannibalism in Triatoma (Reduviidae). J Parasitol. 1951;37:433-4.

84. Marinkelle C. Direct transmission between individuals of Rhodnius prolixus Stal. Rev Biol Trop. 1965;3:55-8.

85. Añez N. Studies on Trypanosoma rangeli Tejera, 1920. III. Direct transmission of Trypanosoma rangeli between triatomine bugs. Mem Inst Oswaldo Cruz. 1982;76:641-7.

86. Schaub G. Direct transmission of Trypanosoma cruzi between vectors of Chagas' disease. Acta Trop. 1988:45:11-9.

87. Lazzari CR, Fauquet A, Lahondère C. Keeping cool: kissing bugs avoid cannibalism by thermoregulating. J Insect Physiol. 2018;107:29-33.

88. Peña VH, Fernández GJ, Gómez-Palacio AM, Mejía-Jaramillo AM, Cantillo O, Triana-Chávez O. High-resolution melting (HRM) of the cytochrome B gene: a powerful approach to identify blood-meal sources in Chagas disease vectors. PLoS Negl Trop Dis. 2012;6:e1530.

89. Hernández C, Salazar C, Brochero H, Teherán A, Buitrago LS, Vera M, et al. Untangling the transmission dynamics of primary and secondary vectors of Trypanosoma cruzi in Colombia: parasite infection, feeding sources and discrete typing units. Parasit Vectors. 2016;9:620.
90. Mutero CM, Kabutha C, Kimani V, Kabuage L, Gitau G, Ssennyonga J, et al. A transdisciplinary perspective on the links between malaria and agroecosystems in Kenya. Acta Trop. 2004;89:171-86.

91. Gottdenker NL, Calzada JE, Saldaña A, Carroll CR. Association of anthropogenic land use change and increased abundance of the Chagas disease vector Rhodnius pallescens in a rural landscape of Panama. Am JTrop Med Hyg. 2011:84:70-7.

92. Sierra CA, Mahecha M, Poveda G, Álvarez-Dávila E, Gutierrez-Velez VH, Reu B, et al. Monitoring ecological change during rapid socio-economic and political transitions: Colombian ecosystems in the post-conflict era. Environ Sci and Policy. 2017;76:40-9.

\section{Publisher's Note}

Springer Nature remains neutral with regard to jurisdictional claims in published maps and institutional affiliations.
Ready to submit your research? Choose BMC and benefit from:

- fast, convenient online submission

- thorough peer review by experienced researchers in your field

- rapid publication on acceptance

- support for research data, including large and complex data types

- gold Open Access which fosters wider collaboration and increased citations

- maximum visibility for your research: over 100M website views per year

At BMC, research is always in progress.

Learn more biomedcentral.com/submissions 